\title{
Efektivitas Kombinasi Insektisida Nabati Daun Sirsak (Annona muricata L.) dan Daun Sirih Hijau (Piper betle) terhadap Mortalitas Ulat Grayak (Spodoptera litura F.)
}

\section{Effectiveness of Combination of Vegetable Insecticides Soursop Leaf (Annona muricata L.) and Green Betel Leaf (Piper Betle) on Mortality of Caterpillar (Spodoptera litura F.)}

\author{
Wira Guna Siswaatmadja*, Albertus Sudirman, Dedy Supriyatdi, Mirodi Syofian \\ Plantation Industry Production and Management Study Program, Politeknik Negeri Lampung, Bandar Lampung, Indonesia \\ ${ }^{*}$ Corresponding author: wiraguna1997@gmail.com
}

Received: May 3, 2021; Accepted: October 30, 2021; Published: October 1, 2021

\begin{abstract}
Armyworm (Spodoptera litura) is a polyphagous pest because it has a diverse host range. Armyworm is an important pest because it can cause crop failure if not controlled. One way to control it is by applying botanical insecticides. Some plants that have the potential to be used as vegetable pesticides include soursop leaf (Annona muricata L.) and green betel leaf (Piper betle L.). This study aimed to examine the effect of the combination of soursop leaf extract (Annona muricata L.) and green betel leaf extract (Piper betle L.) on the mortality of Spodoptera litura $\mathrm{F}$ and to obtain the best concentration of the combination of soursop leaf extract (Annona muricata L.). and vegetable insecticide green betel leaf (Piper betle L.) in the control of armyworm (Spodoptera litura F). The design used was a completely randomized design (CRD) which consisted of 7 treatments with 4 replications so that 28 experimental units were obtained. Vegetable insecticides combined with betel leaf and soursop leaf extract have the potential to control $S$. litura F. with the best concentration in controlling $S$. litura is a concentration of $60 \%$ based on armyworm mortality and killing speed of S. litura F.
\end{abstract}

Keywords: antagonist test; inhibition; larvae

Cite this as: Siswaatmadja, W. G., Sudirman, A., Supriyatdi, D., \& Syofian, M. (2021). Efektivitas kombinasi insektisida nabati daun sirsak (Annona muricata L.) dan daun sirih hijau (Piper betle) terhadap mortalitas ulat grayak (Spodoptera litura F.). Agrosains : Jurnal Penelitian Agronomi, 23(2), 80-83. DOI: http://dx.doi.org/10.20961/agsjpa.v23i2.49130

\section{PENDAHULUAN}

Ulat grayak merupakan hama dari kelompok serangga herbivora yang bersifat polifag, artinya tanaman inang dari serangga tersebut beragam jenis dari famili yang berbeda atau dari ordo yang berbeda. Ulat grayak merupakan hama penting bagi beberapa tanaman perkebunan seperti tembakau, tebu, dan kapas yang dapat menyebabkan gagal panen bila pengendalian tidak dilakukan (Musyahadah et al., 2015). Gejala serangan ulat grayak dimulai sejak fase larva, larva akan merusak daun dan hanya menyisakan epidermis tipis dan tulang daun saja, sehingga proses fotosintesis daun akan terganggu yang menyebabkan produksi tanaman menurun (Kumar, 2020).

Upaya untuk mengatasi serangan ulat grayak pada tanaman umumnya dilakukan dengan menggunakan pestisida. Pestisida yang umumnya digunakan oleh orang Indonesia adalah pestisida kimia yang dianggap lebih praktis dan efisien, padahal pestisida kimia meninggalkan residu kimia yang tinggi pada tanaman dan tanah yang menyebabkan pencemaran (Arfianto, 2018). Menurut Pamungkas et al., (2016) berdasarkan data WHO tahun 2014 tentang bahaya penggunaan pestisida kimia menyebutkan bahwa tiap tahunnya terjadi 1-5 juta kasus keracunan pada sektor pertanian.

Penggunaan pestisida alami menjadi salah satu alternatif yang dapat dilakukan. Pestisida nabati berasal dari bahan alami yang mudah terurai sehingga tidak menyebabkan kerusakan lingkungan (Keswani et al., 2019). Indonesia merupakan negara tropis yang memiliki prospek yang cukup baik dalam pemanfaatan pestisida nabati karena Indonesia memiliki berbagai macam tumbuhan yang mengandung senyawa kimia alami sebagai bahan baku pestisida (Overton et al., 2021).

Senyawa sekunder dari tanaman yang berperan sebagai bahan aktif dalam pestisida nabati dapat berfungsi sebagai penolak, penambah nafsu makan, dan pembunuh serangga hama. Penggunaan beberapa jenis tanaman sebagai bahan pembuatan pestisida nabati diharapkan mampu menekan penggunaan pestisida kimia (Flores et al., 2022). Banyak tanaman yang berpotensi sebagai bahan pembuatan pestisida nabati, diantaranya adalah daun sirsak (Annona muricata L.) dan daun sirih hijau (Piper betle).

Sirsak (Annona muricata L.) merupakan salah satu tanaman buah yang memiliki rasa manis dan asam. 
Tanaman sirsak merupakan tanaman yang memiliki kandungan kimia acetogenin yang dapat dijadikan sebagai insektisida botani, kandungan daun sirsak dengan konsentrasi ekstrak 0,63- 5\% mampu menurunkan laju konsumsi relatif, laju pertumbuhan relatif, dan efisiensi koversi pakan yang dimakan pada larva Spodoptera litura instar V (Ambarningrum et al., 2012). Insektisida biologi yang berasal dari daun sirsak mengandung squamosin dan asimisin yang mampu mengganggu keseimbangan osmotic sel pada larva (Saragih et al., 2015). Kutu daun persik yang diberikan ekstrak daun sirsak dengan konsentrasi yang tinggi mampu menyebabkan mortalitas yang tinggi dikarenakan adanya kandungan isoquanalin alkaloid yang bersifat antifeedant sehingga menyebabkan kematian bagi serangga (Yadav et al., 2021).

Tanaman sirih (Piper betle L.) merupakan tanaman obat yang banyak digunakan oleh masyarakat Indonesia karena mudah didapat. Tanaman sirih mengandung senyawa saponin yang diduga mampu menjadi racun perut bagi larva, senyawa tersebut berdifusi kedalam lapisan kutikula dan menyebar keseluruh tubuh larva (Indiati \& Rahayu, 2017). Kandungan senyawa yang dapat berperan sebagai insektisida pada daun sirih antara lain adalah sianida, saponin, tanin, flafonoid, steroid, alkaloid (Shahdost-fard et al., 2021).

Penelitian ini bertujuan untuk mendapatkan pengaruh kombinasi ekstrak daun sirsak (Annona muricata L.) dan ekstrak daun sirih hijau (Piper betle L.) terhadap mortalitas ulatgrayak (Spodoptera litura F), dan untuk mendapatkan konsentrasi terbaik dari kombinasi ekstrak daun sirsak (Annona muricata L.) dan insektisida nabati daun sirih hijau (Piper betle L.) dalam mengendalikan ulatgrayak (Spodoptera litura F).

\section{BAHAN DAN METODE}

Penelitian ini dilaksanakan di Laboratorium Tanaman Politeknik Negeri Lampung pada bulan Desember 2019 sampai Januari 2020. Alat yang digunakan dalam penelitian ini adalah kurungan serangga, gelas plastik, kertas label, kuas, kain kasa, pisau, timbangan, blender, ember, cawan petri, gela sukur, panci, dan toples. Bahan yang digunakan dalam penelitian ini adalah daun sirih, daun sirsak, akuades, deterjen, larva Spodoptera litura instar II, serbuk gergaji, kertas serap, kapas, madu, dan daun bayam. Penelitian ini menggunakan Rancangan Acak Lengkap yang terdiri atas 7 perlakuan dengan 4 ulangan, sehingga terdapat 28 satuan percobaan. Setiap satuan percobaan terdiri dari 12 ekor larva ulat grayak tahap instar II. Pada pembuatan perlakuan 10\%, jumlah larutan yang dibutuhkan adalah $10 \%$ dari $100 \mathrm{ml}$ larutan jadi, yaitu 10 $\mathrm{ml}$ larutan jadi, lalu ditambahkan dengan $90 \%$ atau 90 $\mathrm{ml}$ akuades.

Data yang diperoleh dianalisis dengan analisis ragam, bila berbeda nyata maka dilanjutkan dengan uji BNT pada taraf $5 \%$.Pengamatan dilakukan setiap hari dengan mengamati jumlah ulat yang mati (mortalitas), dan lama perkembangan larva hingga menjadi pupa setelah pemberian perlakuan insektisida nabati. Mortalitas dihitung menggunakan rumus sebagai berikut:

Mortalitas $\sim \underset{1}{\mathrm{z}}=\frac{\text { Jumlah larva yang mati }}{\text { jumlah seluruh larva yang diamati }} \times 100 \%$

Lama perkembangan larva hingga menjadi pupa diamati setiap hari dengan melihat lama waktu hidup larva hingga menjadi pupa. Data yang diperoleh diolah dengan sidik ragam. Jika hasil analisis sidik ragam menunjukkan perbedaan nyata, maka akan dilanjutkan dengan uji BNT pada taraf $5 \%$.

\section{HASIL DAN PEMBAHASAN}

Berdasarkan hasil analisis ragam (Tabel 1) menunjukkan bahwa pemberian ekstrak kombinasi daun sirsak dan daun sirih dengan tingkat konsentrasi yang berbeda tiap perlakuan berpengaruh terhadap mortalitas S. litura. Hal tersebut dikarenakan adanya kandungan senyawa pada daun sirsak dan daun sirih yang dapat mengendalikan S. litura. Menurut Harahap et al., (2019), pada daun sirsak mengandung senyawa metaboli sekunder, yaitu flavonoid, fenolik, saponin, dan tanin yang bersifat sitotoksit.

Tabel 1. Analisis ragam pada mortalitas hama S. Litura

\begin{tabular}{lllllll}
$\begin{array}{c}\text { Sumber } \\
\text { Keragaman }\end{array}$ & $\begin{array}{c}\text { Derajat } \\
\text { bebas } \\
(\mathrm{Db})\end{array}$ & $\begin{array}{c}\text { Jumlah } \\
\text { Kuadrat } \\
(\mathrm{JK})\end{array}$ & $\begin{array}{c}\text { Kuadrat } \\
\text { Tengah } \\
(\mathrm{KT})\end{array}$ & F hitung & $\begin{array}{c}\mathrm{F} \\
\text { tabel } \\
5 \%\end{array}$ & $\begin{array}{c}\mathrm{F} \text { tabel } \\
1 \%\end{array}$ \\
\hline $\begin{array}{l}\text { Perlakuan } \\
\text { Galat }\end{array}$ & 6 & 11,292 & 1,882 & $24,316^{*}$ & 3 & 3,812 \\
Percobaan & 21 & 1,625 & 0,077 & & & \\
Umum & 27 & 11,292 & & & & \\
\hline
\end{tabular}

Keterangan : ${ }^{*}=$ berbeda nyata

\section{Mortalitas Ulat grayak}

Berdasarkan rerata mortalitas (Tabel 2) menunjukkan bahwa kombinasi ekstrak daun sirsak dan daun sirih berpengaruh terhadap mortalitas ulatgrayak secara nyata. Konsentrasi $60 \%$ (E6) memiliki rerata mortalitas tertinggi yaitu sebesar 3,12 diikuti dengan konsentrasi $50 \%$ (E5) sebesar 2,87 dan berbeda nyata dengan konsentrasi 0\% (Kontrol), 10\% (E1), 20\% (E2), $30 \%$ (E3), dan 40\% (E4). Namun antara konsentrasi $60 \%$ (E6) dan konsentrasi $50 \%$ (E5) tidak berbeda nyata.

Tabel 2. Rerata mortalitas pengaruh kombinasi ekstrak daun sirih dan daun sirsak terhadap mortalitas S. litura

\begin{tabular}{lll}
\hline Perlakuan & Rerata mor \\
\hline E0 (kontrol) & 0,97 & a \\
E1 konsentrasi 10\% & 2,21 & a \\
E2 konsentrasi 20\% & 2,09 & a \\
E3 konsentrasi 30\% & 2,28 & a \\
E4 konsentrasi 40\% & 2,23 & a \\
E5 konsentrasi 50\% & 2,87 & b \\
E6 konsentrasi 60\% & 3,12 & b \\
\hline
\end{tabular}

Keterangan : Angka-angka yang diikuti oleh huruf yang sama pada kolom yang sama menunjukkan tidak berbeda nyata pada uji BNT $5 \%$

\section{Pengaruh Ekstrak Kombinasi Daun Sirsak dan Daun Sirih pada Lama Perkembangan Larva S. litura}

Berdasarkan pengamatan pada lama perkembangan larva dari instar II hingga pupa (Tabel 3) menunjukkan bahwa terdapat pengaruh yang berbeda antara perlakuan dengan konsentrasi 10\% (E1), 20\% (E2), 30\% (E3), 40\% (E4), 50\% (E5), 60\% (E6) dan perlakuan tanpa konsentrasi (Kontrol). Lama perkembangan larva instar II hingga pupa pada perlakuan E1, E2, E3, E4, E5, dan E6 berlangsung 
selama 4 hari sampai dengan 5,60 hari, sedangkan lama perkembangan larva instar II hingga pupa tanpa perlakuan (kontrol) berlangsung selama 7,02 hari. Hal ini diduga terjadi karena kandungan insektisida dari daun sirih dan daun sirsak yang bersifat racun bagi larva Spodoptera litura.

Tabel 3. Lama perkembangan larva $S$. litura akibat perlakuan kombinasi ekstrak daun sirih dan daun sirsak

\begin{tabular}{llll}
\hline Perlakuan & N & $\begin{array}{l}\text { Lama perkembangan instar II- } \\
\text { pupa } \\
\text { (hari } \pm \text { std) }\end{array}$ & \\
\hline E0 (kontrol) & 46 & $7,021 \pm 0,577$ & $\mathrm{~g}$ \\
E1 konsentrasi 10\% & 30 & $5,606 \pm 1,732$ & ef \\
E2 konsentrasi 20\% & 32 & $5,4 \pm 1,633$ & e \\
E3 konsentrasi 30\% & 29 & $4,848 \pm 0,957$ & bc \\
E4 konsentrasi 40\% & 30 & $4,720 \pm 1$ & d \\
E5 konsentrasi 50\% & 17 & $4,3 \pm 0,5$ & ab \\
E6 konsentrasi 60\% & 11 & $4 \pm 0,5$ & a
\end{tabular}

Keterangan: $\mathrm{N}=$ Jumlah larva yang hidup setelah diberi perlakuan, Std $=$ Standar deviasi

Menurut Firmansyah \& Isnaeni, (2020), semakin tinggi ekstrak yang diberikan maka proses pembentukan larva menjadi pupa akan semakin lama dibandingkan dengan kontrol. Larva pada instar lanjutakan mengalami kematian yang ditunjukkan dengan gagalnya proses penggantian kulit yang menyebabkan larva tidak menjadi instar yang lebih besar. Sedangkan prapupa akan gagal dalam pembentukan pupa, sehingga proses terkelupasnya kulit hanya sebagian tubuh saja (Wang et al., 2021).

Berdasarkan Tabel 4. perlakuan E6 (60\%) mengalami peningkatan mortalitas ulatgrayak mulai dari hari ke-1 sampai hari ke-4 setelah aplikasi, yaitu berturut-turut 3,90\%, 4,42\% 6,42\% dan 8,46\%. Hal ini menunjukkan bahwa kombinasi ekstrak daun sirih dan daun sirsak dengan konsentrasi $60 \%$ adalah yang paling efektif berdasarkan waktu tercepat dalam membunuh $\mathrm{S}$. litura dibandingkan perlakuan E1 (10\%), E2 (20\%), E3 (30\%), E4 (40\%), dan E5 (50\%). Menurut Azlansah et al., (2019), bahwa senyawa alkaloid bersifat anti makan sehingga senyawa alkoid tersebut dapat merusak system saraf dan pencernaan, laju pertumbuhan menurun, gagalnya pupa menjadi imago.

Senyawa saponin pada daun sirsak dan daun sirih dapat merusak lapisan lilin pada lapisan kutikula yang menyebabkan ulat kekurangan banyak air dan akhirnya mati. Sedangkan senyawa tannin bersifat antifeedant, menyusut dan mengeringkan jaringan kulit ulat (Qin et al., 2021).

Tabel 4. Rekapitulasi data mortalitas S. litura 1 sampai 4 HSA (Transformasi $\sqrt{\mathrm{X}}$ )

\begin{tabular}{|c|c|c|c|c|c|c|c|c|c|c|c|c|}
\hline \multirow[b]{2}{*}{ Perlakuan } & \multicolumn{3}{|c|}{$1 \mathrm{HSA}$} & \multicolumn{3}{|c|}{2 HSA } & \multicolumn{3}{|c|}{3 HSA } & \multicolumn{3}{|c|}{4 HSA } \\
\hline & $\begin{array}{c}\text { Mortalita } \\
\mathbf{s}\end{array}$ & $\underset{\mathrm{h}}{\text { Jumla }}$ & $\begin{array}{c}\text { Mortalitas } \\
(\%)\end{array}$ & Mortalitas & Jumlah & $\begin{array}{c}\text { Mortalit } \\
\text { as } \\
(\%) \\
\end{array}$ & Mortalitas & Jumlah & $\begin{array}{c}\text { Mortalitas } \\
(\%)\end{array}$ & Mortalitas & Jumlah & $\begin{array}{c}\text { Mortalitas } \\
(\%)\end{array}$ \\
\hline E0 (kontrol) & 0,71 & 0,71 & 1,47 & 0,71 & 1,41 & 1,47 & 0,71 & 2,12 & 1,47 & 0,71 & 2,83 & 1,47 \\
\hline $\begin{array}{c}\text { E1 } \\
\text { konsentrasi } \\
10 \%\end{array}$ & 0,71 & 0,71 & 1,47 & 0,71 & 1,41 & 1,47 & 2,35 & 3,76 & 4,89 & 2,55 & 6,31 & 5,31 \\
\hline $\begin{array}{c}\text { E2 } \\
\text { konsentrasi } \\
20 \%\end{array}$ & 0,71 & 0,71 & 1,47 & 1,58 & 2,29 & 3,29 & 2,12 & 4,41 & 4,42 & 2,12 & 6,53 & 4,42 \\
\hline $\begin{array}{c}\text { E3 } \\
\text { konsentrasi } \\
30 \%\end{array}$ & 0,71 & 0,71 & 1,47 & 1,22 & 1,93 & 2,55 & 2,55 & 4,48 & 5,31 & 2,35 & 6,83 & 4,89 \\
\hline $\begin{array}{c}\text { E4 } \\
\text { konsentrasi } \\
40 \%\end{array}$ & 0,71 & 0,71 & 1,47 & 0,71 & 1,41 & 1,47 & 2,55 & 3,96 & 5,31 & 2,74 & 6,70 & 5,71 \\
\hline $\begin{array}{c}\text { E5 } \\
\text { konsentrasi } \\
50 \%\end{array}$ & 1,58 & 1,58 & 3,29 & 2,12 & 3,70 & 4,42 & 3,24 & 6,94 & 6,74 & 3,24 & 10,18 & 6,75 \\
\hline $\begin{array}{c}\text { E6 } \\
\text { konsentrasi } \\
60 \%\end{array}$ & 1,87 & 1,87 & 3,90 & 2,12 & 3,99 & 4,42 & 3,08 & 7,07 & 6,42 & 4,06 & 11,14 & 8,46 \\
\hline
\end{tabular}

Keterangan : HSA = Hari Setelah Aplikasi

\section{KESIMPULAN}

Insektisida nabati kombinasi ekstrak daun sirsak dan ekstrak daun sirih hijau dengan konsentrasi $60 \%$ mampu mengendalikan S. litura berdasarkan jumlah mortalitas ulatgrayak dan kecepatan dalam membunuh S. litura.

\section{DAFTAR PUSTAKA}

Ambarningrum, T., Setyowati, E., \& Susatya, P. (2012). Nutrisi serta terhadap struktur membran peritrofik larva instar v spodoptera litura F . J. HPT Tropika, 12(2), 169-176.

Arfianto, F. (2018). Pengendalian hama kutu putih (Bemisa tabaci) pada buah sirsak dengan menggunakan pestisida nabati ektrak serai (Cymbopogon nardus L.). Jurnal Daun, 5(1), 1726.

Azlansah, Rusdy, A., \& Hasnah. (2019). Concentration test of jengkol skin extract against armyworm spodoptera litura $f$. At laboratory. Jurnal IImiah Mahasiswa Pertanian Unsyiah, 4(2), 161-167.

Firmansyah, E., \& Isnaeni, S. (2020). Respons pertumbuhan dan perkembangan larva spodoptera litura terhadap aplikasi ekstrak daun Sphagneticola trilobata. Jurnal Agro, 7(1). https://doi.org/10.15575/7409

Flores, P., Hellín, P., Navarro, S., \& Fenoll, J. (2022). Assessment of reclaimed agro-wastewater polluted with insecticide residues for irrigation of growing lettuce ( Lactuca sativa L ) using solar. Environmental Pollution, 292(118367). https://doi.org/10.1016/j.envpol.2021.118367

Harahap, F. S., Walida, H., Harahap, D. A., \& Wicaksono, M. (2019). Pemberian abu sekam padi dan jerami padi untuk pertumbuhan serta serapan tanaman jagung manis (Zea mays I.) pada tanah 
ultisol di kecamatan rantau selatan. Jurnal Agroplasma, 6(2), 12-18. https://doi.org/10.36987/agr.v6i2.675

Indiati, S. R. I. W., \& Rahayu, M. (2017). Diversity of mung bean insect pests and their natural enemies in farmers ' fields in East Java , Indonesia. 18(4), 1300-1307. https://doi.org/10.13057/biodiv/d180403

Keswani, C., Singh, H. B., Hermosa, R., García-estrada, C., Caradus, J., \& He, Y. (2019). Antimicrobial secondary metabolites from agriculturally important fungi as next biocontrol agents.

Kumar, A. (2020). Phytochemistry, pharmacological activities and uses of traditional medicinal plant Kaempferia galanga L. - An overview. In Journal of Ethnopharmacology (Vol. 253). Elsevier Ireland Ltd. https://doi.org/10.1016/j.jep.2020.112667

Musyahadah, N., Hariani, N., Hendra, M., Bioproses, L., Biologi, P. S., Mulawarman, U., Biologi, P. S., \& Mulawarman, U. (2015). Uji efektifitas ekstrak daun tigaron (Crateva religiosa $\mathrm{g}$. forst .) terhadap mortalitas ulat grayak (Spodoptera litura $f$.) ( lepidoptera: noctuidae ) di laboratorium. Prosiding Seminar Sains Dan Teknologi FMIPA Unmul, 1(1).

Overton, K., Hoffmann, A. A., Reynolds, O. L., \& Umina, P. A. (2021). Toxicity of insecticides and miticides to natural enemies in Australian grains: A review. In Insects (Vol. 12, Issue 2, pp. 1-24). MDPI AG. https://doi.org/10.3390/insects12020187

Pamungkas, O. S., Promosi, M., Universitas, K., \& Semarang, D. (2016). Bahaya paparan pestisida terhadap kesehatan manusia 1. Bioedukasi, $X I V(1), 27-31$.

Qin, R., Li, P., Du, M., Ma, L., Huang, Y., Yin, Z., Zhang, Y., \& Chen, D. (2021). Spatiotemporal Visualization of Insecticides and Fungicides within Fruits and Vegetables Using Gold Nanoparticle-Immersed Paper Imprinting Mass Spectrometry Imaging. Nanomaterials, 1327(11).

Saragih, E., Pangestiningsih, Y., \& Lisnawita. (2015). Uji Efektifitas Insektisida Biologi terhadap Hama Penggerek Polong (Maruca testulalis Geyer.) (Lepidoptera; Pyralidae) pada Tanaman Kacang Panjang di Lapangan. Jurnal Online Agroekoteknologi, 3(4), 1468-1477.

Shahdost-fard, F., Fahimi-kashani, N., \& Hormozinezhad, M. R. (2021). Talanta A ratiometric fluorescence nanoprobe using CdTe QDs for fast detection of carbaryl insecticide in apple. Talanta, 221(July 2020), 121467. https://doi.org/10.1016/j.talanta.2020.121467

Wang, Z., Liang, C., Shang, Z., Yu, Q., \& Xue, C. (2021). Insecticide resistance and resistance mechanisms in the melon aphid, Aphis. Pesticide Biochemistry and Physiology, 172(December 2020), 104768. https://doi.org/10.1016/j.pestbp.2020.104768

Yadav, N., Garg, V. K., Chhillar, A. K., \& Rana, J. S. (2021). Detection and remediation of pollutants to maintain ecosustainability employing nanotechnology: A review. Chemosphere, 280, 130792.

https://doi.org/10.1016/j.chemosphere.2021.13079 